\title{
A descrição semiótica no mangá Inu Yasha: análise de personagens
}

\author{
Aline Majuri WANDERLEY (Universidade de São Paulo)
}

RESUMO: O estudo realizado em Inu Yasha, de Rumiko Takahashi, tem como objetivo revelar variados aspectos da cultura e pensamento japoneses, ainda distantes do ocidente. Para tanto, são analisadas as relações semióticas que dão forma às interações entre as personagens principais da saga.

PALAVRAS-CHAVE: mangá; totalidade $v s$ parcialidade; paixões; youkai

\begin{abstract}
The study on Rumiko Takahashi's Inu Yasha has the objective of revealing an array of aspects related to the the japanese culture and thought, yet distant from the east. Thus, we analyse the semiotic relations that give shape to the interactions between the mais characters of the plot.
\end{abstract}

KEYWORDS: manga;totality vs partiality;passions;youkai 


\section{Introdução}

Mangá é o nome pelo qual as histórias em quadrinhos japonesas são conhecidas. Populares em todo o mundo, dividem-se em gêneros específicos para um público cada vez mais variado, indo de crianças em período pré-escolar até os famosos 'salary-man' (empresários japoneses). No entanto, os gêneros mais rentáveis e difundidos do universo dos mangá são os chamados shônen e shôjo. Os mangá shônen são dedicados a garotos adolescentes-como é o caso de Inu Yasha- enquanto os shôjo, às garotas da mesma faixa.

Não se pode falar em mangá moderno sem mencionar a importância de Rumiko Takahashi. Uma das artistas de quadrinhos japoneses mais respeitadas e famosas não só no Japão, mas em diversos países, tendo vendido mais de 100 milhões de volumes de suas obras. Seus mangá são publicados na América Latina, Ásia e Europa (curiosamente, são nos países latinos europeus que suas histórias fazem mais sucesso).

Seu mais recente trabalho, Inu Yasha- Um conto de fadas feudal, conta a história de Kagome Higurashi, uma colegial do Japão moderno que volta 500 anos no tempo até a Era Sengoku Jidai (final do século XV até XVI), mais conhecida como o período de guerras entre os senhores feudais japoneses (daimyos), a época mais sangrenta da História do Japão.

Lá e então, a garota encontra um meio-youkai, ou meio-demônio (denominado hanyou) que, cinqüenta anos antes, havia sido aprisionado por uma sacerdotisa (no original, miko) de nome Kikyou. Este hanyou, chamado Inu Yasha, havia aterrorizado uma vila em busca de um artefato de poderes extraordinários, a Jóia de Quatro Almas (Shikon no Tama). A sacerdotisa, cujo dever era cuidar para que a Jóia não caísse em mãos erradas, falece logo após aprisionar Inu Yasha. Assim, cinqüenta anos depois, a jovem Kagome consegue libertá-lo, revelando poderes que até então desconhecia, e ainda descobre que ela própria é a reencarnação da falecida Kikyou. Além disso, a Jóia, que fora queimada junto ao cadáver de Kikyou, reaparece na Era Feudal ao sair do corpo de Kagome.

Kagome, ao atirar uma flecha para recuperar a Jóia que havia sido roubada por um corvo, quebra o artefato em inúmeros fragmentos que se espalham por todo o território japonês medieval. Como até um simples fragmento é gerador de imenso poder, seria preciso evitar que caíssem em mãos malignas. Coube, portanto, a Inu Yasha e Kagome recuperarem todas as partes da Jóia. Ele, pela força resultante de sua origem meio demônio (youkai) e meio humana, e seu desejo de tornar-se um ser completo (seja este somente humano ou somente youkai); ela, por ser a única capaz de detectar a presença dos fragmentos, por conta dos poderes herdados da falecida sacerdotisa.

Em sua busca, o casal depara-se com diversos inimigos, sendo eles humanos ou youkai, todos atrás dos poderes magníficos da Jóia. Eles encontram o mais perigoso de todos, Naraku, um meio-youkai assim como Inu Yasha. Naraku busca a Jóia de Quatro Almas para tornar-se um youkai completo extremamente poderoso. Na verdade, fora Naraku que, cinqüenta anos atrás, semeara a discórdia entre Inu Yasha e Kikyou, fazendo com que um sentisse ódio ao outro (ver item 2., Kikyou). No decorrer da 
narrativa, Inu Yasha descobre a verdadeira face de Naraku, e este se torna seu principal inimigo.

Durante a saga, juntam-se a Inu Yasha e Kagome três companheiros: Shippou, um youkai (demônio) raposa criança, que teve seus pais assassinados; Miroku, uma espécie de monge budista (no original, houshi) cujo objetivo é destruir Naraku, já que este colocou uma maldição em sua família; e Sango, uma exterminadora de youkai cuja família e clã foram dizimados por uma armadilha do mesmo Naraku e que agora busca vingança.

Na narrativa ainda ressurge Kikyou, revivida por uma feiticeira maligna. Kikyou volta à vida com o mesmo corpo que tinha cinqüenta anos antes, e sobrevive com almas roubadas de mortos (já que parte de sua alma está com Kagome, sua reencarnação) e com o ódio com o qual morrera. Outro personagem é o irmão mais velho de Inu Yasha, o senhor Sesshoumaru. Diferente daquele, Sesshoumaru é um youkai completo, que nutre um desafeto muito grande pelo irmão por este ser metade humano. Desprezando humanos, ele está em busca da espada de Inu Yasha, a Tessaiga (no original, Tetsusaiga), herança do pai, um poderoso youkai cachorro, ao irmão mais novo.

O palco está montado: o grupo parte em busca dos fragmentos por uma terra habitada por diferentes seres, que aparecerão para enriquecer ainda mais a história.

\section{A Semio-narratividade}

A categoria semântica mais articulada na obra é totalidade $v s$ parcialidade. Pensando logo no próprio ambiente em que ela se passa, tem-se a articulação da categoria. Na Era Feudal, o Japão encontrava-se dividido em territórios, cada qual comandado por um senhor. O país situava-se em terreno da parcialidade, em oposição à totalidade, um Japão totalmente unificado; a interação das duas épocas da história, o Japão Feudal e o moderno, graças às viagens temporais de Inu Yasha e Kagome, também formam uma totalidade, assim como a relação dos seres fantásticos com os humanos, que convivem lado a lado, um sem estranhar a presença do outro. Analisemos as personagens.

Inu Yasha- A categoria semântica articulada é totalidade $v s$ parcialidade, eufórico e disfórico respectivamente. Inu Yasha encontra-se em terreno da parcialidade, já que é metade humano e metade youkai, e o que deseja é tornar-se um ser total. O sujeito narrativo, em conjunção com os valores da parcialidade disforizada, torna-se retenso. Sendo assim, durante toda a narrativa, procura transformar esse estado caminhando para o relaxamento, que só ocorre quando entra em conjunção com os valores da totalidade.

Já em nível narrativo, estabeleceu-se um contrato polêmico entre os humanos e youkai (sujeito do ser) e Inu Yasha (sujeito do fazer). Como nos diz Pietroforte (2003: $52)^{1}$, no contrato polêmico, o sujeito do ser espera que o do fazer coloque-o em conjunção com os valores disforizados, no caso, os da parcialidade. Isso ocorre, pois Inu Yasha é um meio-demônio, fato percebido negativamente pelos dois grupos. Como o sujeito do fazer colocou o do ser em conjunção com a parcialidade, surge como efeito a 
intimidação: Inu Yasha era desprezado pelos humanos, que não o deixavam participar do convívio social. O sujeito do fazer ainda sofre provocação quando deste é oferecida uma imagem negativa: os youkai julgam Inu Yasha como fraco por sua metade humana, e estes julgam-no um demônio, por sua metade youkai. A provocação determina o ser do sujeito- já que ele a julga verdadeira- entrando em conjunção com o saber-ser que conhece sua situação. Está em conjunção ainda, com o poder-ser, já que é livre para mudar seu estado. A intimidação determina o vir a ser em conjunção com o dever-ser: o sujeito do fazer, Inu Yasha, entrando em conjunção com a totalidade, coloca o do ser em conjunção com os valores euforizados, gerando a paixão da temperança. No percurso da ação, verifica-se a conjunção do sujeito com o saber-fazer: este é figurativizado por Kagome, já que ela é a única que pode detectar os fragmentos e fazer com que o sujeito entre em conjunção com o objeto de valor, a Jóia. No entanto, apesar de estar em conjunção com o saber-fazer, ou seja, ser competente nesse aspecto, o sujeito também está em conjunção com o não-poder fazer, ou seja, no momento ele é impotente. Isso se explica porque o seu poder-fazer é figurativizado por sua espada Tessaiga. Há de se verificar, ainda, duas dimensões nesse objeto modal: a do poder, ou seja, a arma propriamente dita, e a do saber-fazer, já que Inu Yasha ainda está em fase de aprendizagem, descobrindo aos poucos como manipular corretamente a sua espada. Esta, portanto, não é forte o suficiente, por enquanto, para derrotar Naraku e conseguir a Jóia.

Em conjunção com o saber-fazer e com o não-poder-fazer, esse sujeito ainda não é apto para realizar a perfórmance. A Inu Yasha só resta aumentar o poder da espada aprendendo a usá-la corretamente, com todos os tipos de ataques e defesas, para assim, entrar em conjunção com o poder-fazer.

Kagome-Lembrando que a garota é reencarnação de Kikyou, e possui dentro de si uma alma somente sua, e uma parte que diz respeito à de Kikyou, tem-se também a categoria articulada por totalidade $v s$ parcialidade, com os valores da totalidade euforizados, e os da parcialidade disforizados. O estado do sujeito é o seguinte: antes de saber da existência de Kikyou, Kagome tinha certeza de sua totalidade. Era um sujeito relaxado por estar em conjunção com os valores eufóricos. Sendo assim, sua tendência é manter a continuação desse estado. No entanto, a chegada de outro sujeito, figurativizado pela Kikyou renascida, impede- o de realizar a manutenção de seu estado. Ele, então, entra em contenção, uma vez que surge a parada da continuação, com a conjunção com o estado de não totalidade. Kagome percebe que não é mais total. Agora, com o 'fantasma' de Kikyou a aterrorizá-la, ela é híbrida, possuindo uma parte da sacerdotisa. Assim, em conjunção com a parcialidade, entra em estado de retenção, com uma continuação da parada. O que resta ao sujeito é tentar caminhar de volta ao estado inicial de relaxamento, buscando a parada da parada, entrando em distensão, negando o seu estado, ou seja, estando em conjunção com a não-parcialidade. Por isso mesmo, no nível narrativo, Kagome tenta reafirmar-se para com sua ética e valores, e assim afirmar a totalidade de seu ser, distanciando-se de Kikyou, de acordo com suas próprias atitudes.

Para tanto, verifica-se que, em nível narrativo, o sujeito do ser é o mesmo que o do fazer, surgindo as paixões de acionamento, típicas do vir a ser regido pelo querer-ser: 
Kagome deseja distanciar-se de Kikyou e afirmar a sua própria identidade segundo os seus valores. Em conjunção com o querer-fazer, o sujeito entra no processo de aquisição de competência. Ao quebrar acidentalmente a Jóia (ver item 1), Kagome decepciona-se consigo mesma por não ter sido capaz de proteger o artefato; o sujeito está em conjunção com o não-poder-fazer, pois assumiu para si uma competência que não se comprovou. Revoltada com si própria, Kagome tenta reparar a situação, indo em busca dos fragmentos juntamente com Inu Yasha. Para tanto, o sujeito está em conjunção com o saber-fazer que, figurativizado, diz respeito à capacidade de Kagome de sentir a localização dos fragmentos, resultado dos poderes da sacerdotisa que vivem nela. Entretanto, o que se vê é que Kagome não tem posse de todos os fragmentos, já que a maior parte deles está com Naraku. O jeito de consegui-los é derrotando-o, e para isso, Kagome tem como arma um arco e flecha. Assim como em Inu Yasha, há duas dimensões nesse que se torna o objeto modal do poder-fazer do sujeito: a do poder, que é a própria arma, e a do saber, que é o processo de aprendizagem do sujeito para manejar corretamente o objeto. Kagome, apesar de possuir flechas purificadoras (no original, Hama no $\mathrm{Ya}$ ) com a incrível capacidade de destruir presenças malignas, ainda não consegue matar Naraku; não é forte o suficiente, não tendo realizado ainda a perfórmance.

Shippou- Órfão, o pequeno youkai raposa une-se ao grupo de Inu Yasha. Temse a categoria semântica totalidade vs parcialidade, sensibilizados pelo sujeito como eufóricos e disfóricos, respectivamente. Isso se dá porque para Shippou, existe a necessidade de estar no grupo, com todos os seus elementos formando uma totalidade. Em contrapartida, esse sujeito disforiza os valores da parcialidade, que seria a separação de todos os seus membros, ficando Shippou, sozinho. Aqui, o sujeito já se encontra em conjunção com os valores da totalidade que, euforizados, torna-o relaxado, investindo na manutenção desse estado.

Um contrato fiduciário, portanto, foi estabelecido entre ele (sujeito do ser) e o grupo (figurativizado por Inu Yasha \& cia., o sujeito do fazer), em que este coloca aquele em conjunção com o objeto de valor. Em outras palavras, o grupo tem que assim continuar, e não abandonar ou deixar para trás o pequeno Shippou. O sujeito do ser, em conjunção com o dever-ser, esteve em espera fiduciária para que o do fazer o colocasse em conjunção com o objeto de valor. Como isso ocorre, ou seja, o sujeito do fazer cumpre o contrato, a confiança entre eles é reafirmada e surgem as paixões complexas, próprias do dever-ser. Sendo assim, o sujeito do ser em conjunção com o objeto de valor sente as paixões da satisfação e da gratidão pelo cumprimento do contrato.

Miroku- Naraku lançou uma maldição na família de Miroku, em que todos os seus membros nascem com um buraco na mão direita capaz de sugar tudo, até mesmo seu portador. A presença do buraco ("O Buraco do Vento"), portanto, pressupõe a morte e o fim da linhagem, já que Miroku é o último representante da família. Para acabar com a maldição, é preciso matar quem a lançou, e com esse objetivo, o monge Miroku unese ao grupo de Inu Yasha a fim de obter todos os fragmentos da Jóia, impedindo que Naraku os consiga, fortalecendo-se e dificultando o plano traçado pelo monge. A categoria é totalidade vs. parcialidade, com os valores da totalidade representando a 
continuação da linhagem, euforizados, e os da parcialidade, sua extinção, disforizados. O sujeito encontra-se em conjunção com a parcialidade, já que Miroku, morrendo pela maldição, encerra a linhagem. Portanto, procura sair do estado de retenção e caminhar para o de distensão, em conjunção com os valores da não-parcialidade. Isso se dá quando o monge pergunta às garotas se estas não gostariam de ter um filho com ele, negando seu estado. O relaxamento dá-se em conjunção com os valores da totalidade, que afirmam a vida, já que esta é a continuação da linhagem.

Passando para o percurso narrativo, verifica-se o estabelecimento do contrato fiduciário entre o sujeito do ser, figurativizado pelos 'descendentes' de Miroku, que esperam que seu representante não morra e extinga a família, e o sujeito do fazer, Miroku, em conjunção com o dever-fazer. No percurso da ação, o sujeito precisa adquirir competência; verifica-se a conjunção com o saber-fazer, já que Miroku é de todos o mais sábio (ver item 3. Nível Discursivo) e sabe que para destruir a maldição, é preciso destruir Naraku. Quanto ao poder-fazer, apesar de possuir os 'poderes espirituais de Buda', um 'cajado' e 'manuscritos' abençoados, o sujeito encontra-se em conjunção com o não-poder-fazer, pois ainda não é páreo para Naraku.

Sango- A personagem, juntamente com sua família, fazia parte do clã de exterminadores de youkai. Certa vez, ela e o clã foram chamados a um castelo, pelo senhor deste, para destruir um demônio. No entanto, a situação revela-se uma mentira: o senhor do castelo parecia sê-lo mas não era, apresentando-se como Naraku que, na armadilha, dizima todo o clã menos Sango. A categoria semântica é totalidade vs parcialidade, eufórico e disfórico respectivamente. Como parte de um clã, o sujeito encontrava-se em conjunção com os valores da totalidade euforizados, em relaxamento. Quando os exterminadores foram destruídos, a condição de relaxamento é negada, e o sujeito entra em contenção, em conjunção com a não-totalidade. Por fim, como única sobrevivente, o sujeito entra em conjunção com a parcialidade disforizada, tornando-se retenso. A tendência é portanto, voltar a um estado de relaxamento, conseguido por meio da vingança.

Em nível narrativo tem-se o contrato fiduciário, o dever-ser e o dever-fazer: os exterminadores (sujeito do fazer) deveriam derrotar o youkai para o senhor do castelo (sujeito do ser). Como tudo não passara de uma armadilha, há a quebra do contrato fiduciário que instaura no sujeito um vir a ser estabelecido pela conjunção com o deverser, tornando-se uma vingança. Agora, o sujeito, apaixonado pela cólera, tratará para que o sujeito do ser (Naraku) entre em conjunção com os valores disfóricos da parcialidade, impedindo-o de conseguir a Jóia, matando-o para assim, finalizar sua vingança. Em conjunção com o dever-fazer, o sujeito entra no percurso da ação para adquirir competência. Revela-se em parte competente, em conjunção com o saber-fazer: matando Naraku, terá a vingança. No entanto, a conjunção com o não-poder-fazer tornao impotente: apesar de treinada em técnicas ninja, saber manejar armas, venenos, a força de Sango é visivelmente menor à do vilão, e, tendo consciência disso, une-se ao grupo de Inu Yasha para quem sabe, conseguir um dia o seu intento.

Kikyou- Antes de morrer, a categoria estabelecida é totalidade $v s$ parcialidade, sendo os valores da totalidade euforizados, e os da parcialidade, disforizados. Isso se 
dava porque então, Kikyou, além de mulher, era sacerdotisa, sua função consistia somente em proteger a Jóia de seres malignos, não podendo demonstrar fraqueza.

O sujeito encontra-se em conjunção com os valores da parcialidade, estando em retenção. Sua disposição era mudar seu estado, entrando em relaxamento em conjunção com os valores euforizados da totalidade. Para tanto, Kikyou precisava que a Jóia desaparecesse, purificada com um desejo benigno, tornando-se uma garota qualquer. O sujeito torna-se o ser total mulher e entra em relaxamento.

Quando renasce, a categoria ainda é totalidade vs parcialidade, eufórica e disfórica respectivamente. O sujeito está em conjunção com a parcialidade, disforizada, tornando-o retenso. A Kikyou renascida possui apenas uma parte de sua alma (aquela referente ao seu ódio), já que o restante encontra-se em Kagome, sua reencarnação. Para "viver", a sacerdotisa precisa de outras almas de mortos. Kikyou não é então, um ser total, encontrando-se no terreno da parcialidade. Sua disposição é entrar em conjunção com a totalidade, euforizada: para Kikyou, a totalidade refere-se à morte, porque sendo assim, morreria como "ela mesma", após realizar a vingança, que nega o estado de parcialidade, entrando em distensão, caminhando para o relaxamento.

Quanto ao nível narrativo, também se têm os dois momentos: em vida, Kikyou e Inu Yasha, apaixonados, combinaram que ela daria a ele a Jóia de Quatro Almas, virando uma garota qualquer, e ele tornar-se-ia um humano, para que assim, pudessem viver juntos. Os sujeitos estabelecem um contrato fiduciário em que o sujeito do ser (Kikyou), espera que o sujeito do fazer (Inu Yasha) a coloque em conjunção com o objeto de valor totalidade. Entretanto, no dia que fora marcado para Kikyou entregar a Jóia a Inu Yasha, Naraku toma a aparência daquele, fere Kikyou e ainda rouba dela o artefato. Aquele 'Inu Yasha' era uma mentira, ou seja, parecia sê-lo mas não o era. Entretanto, Kikyou morre dos ferimentos sem descobrir a verdade, o sujeito acreditando que houvera rompimento de contrato.

Quando é ressuscitada, Kikyou está repleta de cólera e rancor, paixões típicas do rompimento de um contrato fiduciário, porque para ela, o sujeito do fazer Inu Yasha não cumprira o que ambos haviam estabelecido. Ao descobrir que a quebra de confiança fora causada por Naraku, imediatamente estabelece-se entre ambos um contrato polêmico (ver item 2.A Semio-narratividade, Inu Yasha), já que o sujeito do ser (Naraku) e o sujeito do fazer (Kikyou, já que ela descobriu a verdade sobre Naraku e agora busca vingança) estão em disjunção. O sujeito do ser espera que o sujeito do fazer não o coloque em conjunção com o objeto de valor, figurativizado pela Jóia. No entanto, não é isso o que ocorre: Kikyou consegue uma parte do artefato e o entrega a Naraku. Agora é ela que constitui uma mentira: apesar de parecer estar ajudando-o, na verdade quer destruí-lo por completo.

O sujeito do fazer entra no percurso da ação em conjunção com o dever- fazer, ou seja, devendo conseguir os fragmentos para Naraku e assim realizar sua vingança, para morrer em paz, como "ela mesma". Na aquisição de competência, tem-se a conjunção com o saber-fazer, do mesmo tipo do sujeito da figura Kagome, ou seja, a capacidade de detectar os fragmentos da Jóia. Mas, no momento, o sujeito também está em conjunção com o não-poder-fazer, pois, apesar de possuir os poderes de sacerdotisa e as mesmas flechas purificadoras, ainda não é capaz de sobrepujar a força de Naraku. 
Sesshoumaru- Irmão mais velho de Inu Yasha, despreza humanos por considerá-los seres inferiores. Ele é um demônio completo e passa praticamente toda a saga tentando conseguir a espada Tessaiga de seu irmão (ver item 1.Introdução). Mais uma vez, tem-se a categoria totalidade $v s$ parcialidade, sendo os valores da totalidade euforizados e os valores da parcialidade disforizados. Isso significa que, para Sesshoumaru, a posse da Tessaiga é estar com o total poder do pai, já que ele também recebera de herança uma outra espada, a Tenseiga. Portanto, com a Tenseiga e Tessaiga, Sesshoumaru teria a totalidade do poder de seu grande pai, o que o tornaria um youkai ainda mais poderoso. Em contrapartida, não estando com a posse da Tessaiga, o irmão mais velho de Inu Yasha teria apenas a parcialidade, parte de seu poder.

Vê-se então, que o sujeito encontra-se em conjunção com os valores da parcialidade que, disforizados, torna-o um sujeito em retenção, que procura transformar seu estado até chegar ao relaxamento, entrando em conjunção com os valores da totalidade. Há de se notar também, que Sesshoumaru é uma personagem extremamente cruel, crueldade esta que se encontra igualmente na parcialidade: a Tessaiga só pode ser usada por quem ama e deseja proteger os humanos, e Sesshoumaru, como já visto, não possui nenhuma intenção de ajudá-los, e por isso mesmo não consegue usar a espada.

Em nível narrativo, tem-se o acionamento das paixões típicas do querer-ser: o sujeito entra no percurso já apaixonado, não tendo sofrido manipulação prévia, com um vir a ser regido pela conjunção com o querer-ser. O sujeito do ser também é o do fazer, e por isso mesmo, surgem aqui as paixões de acionamento. Em outras palavras, como já visto, Sesshoumaru, quer e tenta conseguir a Tessaiga de Inu Yasha, em busca de mais poder. A paixão gerada, portanto, é a da ambição. Em conjunção com o querer-fazer, cabe ao sujeito, no percurso da ação, adquirir competência.

O que se vê, é a conjunção do sujeito com o saber-fazer: Sesshoumaru é uma personagem extremamente inteligente e sabe que, para conseguir o poder total do pai, precisa da Tessaiga e com o poder-fazer, já que Sesshoumaru é forte o suficiente para conseguí-la de Inu Yasha. No entanto, o sujeito está em conjunção com o não-poder-ser: somente conscientizando-se em ajudar os humanos que Sesshoumaru seria capaz de manejar a Tessaiga. Ele não realiza a perfórmance, apesar de continuar buscando o objeto.

Naraku- Assim como Inu Yasha, é um meio-youkai. Naraku deseja a Jóia para tornar-se um ser completo, no caso, um demônio completo. Tem-se a categoria da totalidade vs parcialidade, sendo aquela euforizada, e esta, disforizada. Claramente, o sujeito está em conjunção com a parcialidade e em disjunção com a totalidade. Em retenção, procura o relaxamento, que acontece quando o sujeito estiver em conjunção com os valores eufóricos, figurativizados pela Jóia, no nível discursivo.

Como Sesshoumaru, com esse sujeito não há manipulação prévia; sendo ao mesmo tempo o sujeito do ser e do fazer, entra em conjunção com o querer-ser que determina o seu vir a ser, gerando a paixão da ambição. Naraku quer obter a Jóia que para ele seria a forma de tornar-se um ser completo de total poder. O sujeito entra no percurso da ação em conjunção com o querer-fazer, resultante de sua vontade de transformar o seu estado de disjunção com o objeto de valor em conjunção. Na competência, encontra-se em conjunção com o saber-fazer: Naraku possui aliados (e 
não tão aliados, como Kikyou) funcionando como seu objeto modal de saber-fazer. São eles que vão atrás dos fragmentos e descobrem sua localização. Contudo, o sujeito está em conjunção com o não-poder-fazer. Naraku, apesar de poderoso, sofre interferências de Inu Yasha e grupo, que não querem que o vilão consiga a Jóia. Assim, ele é impedido de completá-la, e por isso mesmo, investe em sua força, adquirindo poder suficiente para derrotar seus inimigos e não ter nenhum empecilho. O sujeito ainda não realizou a perfórmance.

\section{Nível discursivo}

Rumiko Takahashi, em Inu Yasha, criou um universo repleto de lendas, personagens fantásticas, ambientalizado em um Japão do passado e do presente. Podem ser percebidos, pois, diversos temas na obra que a seguir, veremos como se relacionam às diversas figuras de Inu Yasha.

Ao se observar a época do Japão Feudal-Sengoku Jidai-em que se passa a maior parte da história, percebe-se o tema político: o país encontrava-se em guerras por posse de terras, já que todo o território estava dividido entre grandes senhores feudais, e por isso não havia unidade na nação. Esse tema é figurativizado pelas imagens das várias aldeias miseráveis pelas quais o grupo de Inu Yasha passa, sofrendo com as constantes batalhas e pela presença de exércitos, senhores feudais, como por exemplo, aquele com o qual a personagem Sango estabelece um contrato.

Além do tema político, há também o tema erótico, figurativizado, por exemplo, pela imagem do monge Miroku, o 'monge devasso', sempre procurando lindas mulheres para perguntar a elas se não gostariam de ter um filho dele. Miroku também investe em cantadas físicas, assediando as garotas ao passar a mão em suas partes íntimas. O tema erótico ainda aparece nas figuras de mulheres e homens despidos.

O tema mais notável em Inu Yasha é o mitológico, já que a história é povoada por seres de lendas japonesas. Essas criaturas convivem lado a lado com os humanos, revelando um aspecto cultural japonês: as lendas mostram que seres humanos e fantásticos coexistem normalmente, um interagindo com o outro. O tema mitológico é figurativizado pelas imagens de seres como youkai, mononoke, oni. Na verdade, youkai é um grupo que engloba todas as outras categorias de demônios e derivados. Subdividem-se em dois grandes grupos, Oni e Mononoke. Os Oni representam o mal na natureza; exemplo dele é Naraku. Já os Mononoke representam o bem da natureza, mas apesar disso, matam humanos, por considerá-los serem inferiores que destroem o meio ambiente. Inu Yasha e Sesshoumaru são Mononoke.

Há ainda o tema religioso, budista e xintoísta. O tema budista é figurativizado pela personagem Miroku que é um Houshi, ou seja, o último nível da gradação para tornar-se efetivamente um monge budista. Há ainda, presença de monges, templos e cerimônias, como por exemplo, a prática de mumificação budista, realizada com o monge ainda em vida, para alcançar a iluminação. Preceitos budistas também são figurativizados em Kagome, pela reencarnação.

O tema xintoísta é forte na trama, por conta de uma das suas figuras principais: a Jóia de Quatro Almas. O conceito da Jóia vem de uma corrente do Xintoísmo, religião 
primitiva japonesa. Nela, acredita-se que existem quatro almas nos seres vivos, minerais e vegetais: Ara-mi-tama, o espírito de governar com autoridade, Nigi-mi-tama, o encarregado de guiar para harmonia ou união, Kushi-mi-tama, o que causa transformações misteriosas e por fim o Saki-mi-tama, que compartilha benção. A palavra tama, que é usada, significa 'bela jóia' ou 'pedra misteriosa', para descrever o espírito ou a alma. Por isso a denominação Shikon no Tama, Jóia de Quatro Almas.

Quando as quatro almas estão em harmonia, tem-se o Naohi e o espírito fica equilibrado, e quando elas estão em desequilíbrio, tem-se o Magatsuhi, fazendo com que se tornem malignas.

Em Inu Yasha, cada alma representa um valor: Ara-mi-tama a Coragem, Nigimi-tama a Amizade, Kushi-mi-tama a Sabedoria, e Saki-mi-tama o amor. Cada um dos personagens principais figurativiza uma alma: Inu Yasha a da Coragem, por seu caráter valente; Shippou a da Amizade, por seu sentimento para com o grupo; Miroku a Sabedoria, já que é ele quem tem os conhecimentos e ensinamentos para passar aos demais, e Sango, o Amor, aquilo que sente em relação aos seus companheiros e família. Já Kagome, em parte sacerdotisa, figurativiza a própria Jóia, união das quatro almas. Lembre-se que inicialmente, a Jóia encontrava-se em seu corpo formando uma totalidade; agora, fora de si e fragmentada, cada um de seus amigos representa um aspecto dela, afirmando mais uma vez a categoria trabalhada. O tema xintoísta ainda aparece na figura da casa de Kagome, um santuário xintoísta, e em seu avô, que cuida das cerimônias.

No nível discursivo, as paixões sofrem o que se chama lexicalização, recebendo fatores culturais ou seja, elas são definidas de acordo com cada cultura.

Viu-se acionamentos das paixões do querer-ser, como em Naraku, que com o seu querer-ser, almeja mais força e poder, caracterizando a ambição, e em Sesshoumaru, que ambiciona mais poder figurativizado pela espada Tessaiga.

Viu-se também, a ocorrência de duas quebras de contrato que geram, no nível discursivo, a paixão da cólera, determinando a vingança, como no caso de Kikyou e Sango. O rompimento da confiança em ambos os casos determina uma reparação e o programa de vingança contra o outro sujeito. Entra, neste ponto, a lexicalização da paixão, como ela é vista em determinadas culturas. Em Inu Yasha, a vingança é vista como um meio de tornar as coisas iguais ou seja, somente depois de vingar-se é que se pode relaxar e seguir em frente: quando Sango vingar-se do Naraku, ela poderá viver em paz e quando Kikyou vingar-se dele, ela poderá finalmente morrer.

Em suma, o mangá em questão é complexo; diversos temas e figuras permeiam a obra enriquecendo-a e divulgando a leitores ocidentais um pouco dos vários aspectos da rica cultura japonesa, considerada ainda tão distante e exótica.

\section{REFERÊNCIAS BIBLIOGRÁFICAS:}

PIETROFORTE, Antonio Vicente (Org.) (2003). A Semiótica das paixões: Introdução e desenvolvimentos. SADI, p.52.

TAKAHASHI, Rumiko. (1997) Inu Yasha.Trad. Arnaldo Massato Oka. São Paulo:

JBC.[ em publicação no Brasil desde 2002]. 


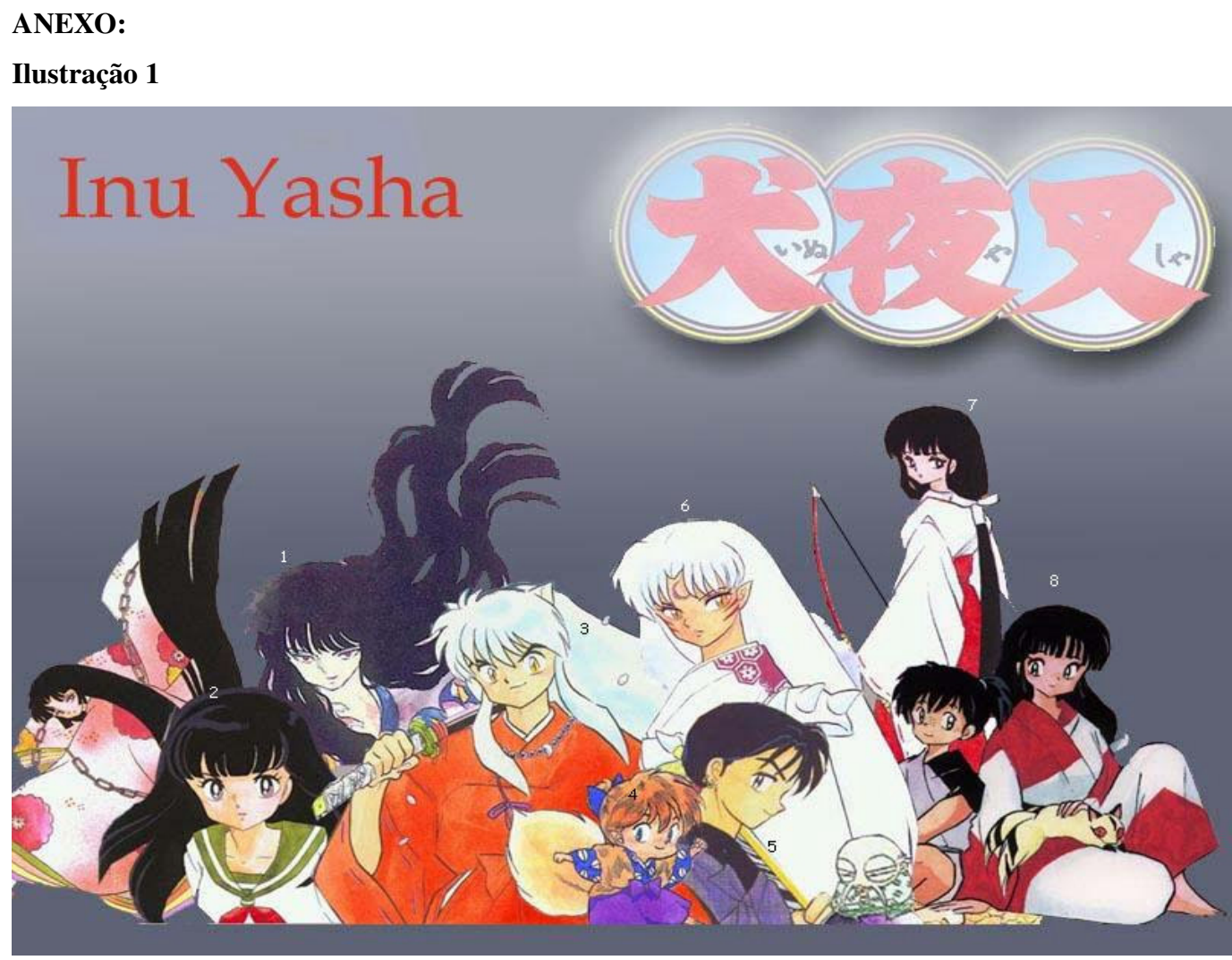

1.Naraku; 2.Kagome; 3.Inu Yasha; 4.Shippou; 5.Miroku; 6.Sesshoumaru; 7.Kikyou; 8.Sango

\section{Como citar este artigo:}

WANDERLEY, Aline Majuri. A descrição semiótica no mangá Inu Yasha: análise de personagens. Estudos Semióticos, Número 2, São Paulo, 2006. Disponível em <www.fflch.usp.br/dl/semiotica/es>. Acesso em "dia/mês/ano". 